\title{
Dural calcification and calvarial hyperostosis: a rare cause of obstructive hydrocephalus in 'malignant' osteopetrosis
}

\author{
Abdul Razik, Ankur Goyal, Arun Kumar Gupta
}

Department of Radiodiagnosis, All India Institute of Medical Sciences (AllMS), New Delhi, India

\section{Correspondence to} Dr Ankur Goyal, ankurgoyalaiims@gmail.com

Accepted 19 August 2015
To cite: Razik A, Goyal A, Gupta AK. BMJ Case Rep Published online: [please include Day Month Year] doi:10.1136/bcr-2015212283

\section{DESCRIPTION}

A 5-year-old boy, born to first-degree consanguineous parents, presented with failure to thrive, recurrent respiratory infections and progressive head deformity since birth, with recent difficulty in walking. Physical examination revealed pallor, scaphocephaly and hepatosplenomegaly. Haemoglobin, leucocyte and platelet counts were $5 \mathrm{~g} / \mathrm{dL}, 4300 /$ $\mathrm{mm}^{3}$ and $100000 / \mathrm{mm}^{3}$, respectively. Skeletal survey demonstrated thickened, densely sclerotic bones with loss of medullary space. A diagnosis of autosomal recessive osteopetrosis (AROP) was made.

Non-contrast CT of the head showed diffuse hyperostosis of skull bones with narrowing of bilateral optic canals and skull base foramina (figure 1A). The sagittal suture could not be identified (premature fusion) and the skull was scaphoid shaped (increased anteroposterior diameter; figure 1B). There was extensive thickening and calcification of the falx cerebri and tentorium cerebelli (figure $2 \mathrm{~A}-\mathrm{C}$ ) with resultant reduction in the capacity of posterior fossa (figure 2C). Consequently, the aqueduct was narrowed with proximal triventricular hydrocephalus and periventricular ooze. Mild cerebellar tonsillar herniation was also seen.

AROP is a rare disorder resulting from defective bone resorption by osteoclasts. This particular form is also known as 'malignant' osteopetrosis owing to its early onset (in infancy) and rapid downhill clinical course. Most cases do not survive beyond 5 years; the only definitive treatment is early bone marrow transplantation. Intracranial manifestations in AROP are varied, and the most common and prominent findings are diffuse thickening and sclerosis of the skull bones. Encroachment and narrowing of optic canal, petrous carotid canal, jugular and vertebral foramina as well as other skull base foramina can result in distressing neurological symptoms, although complications from vascular stenosis are rare. ${ }^{1}$ Hydrocephalus in AROP can either be communicating (attributable to dural venous sinus stenosis or narrowed foramen magnum) or non-communicating, resulting from posterior fossa crowding. The latter occasionally causes tonsillar herniation, bringing in a mixed aetiology to the hydrocephalus. Prompt diversion by ventricular shunt is necessary to prevent irreversible neurological damage, with endoscopic third ventriculostomy having been reported as a newer effective option in cases of non-communicating hydrocephalus. ${ }^{2}$

The cranial findings in this case of AROP are unique because the CT scan showed marked thickening and calcification of the falx cerebri and
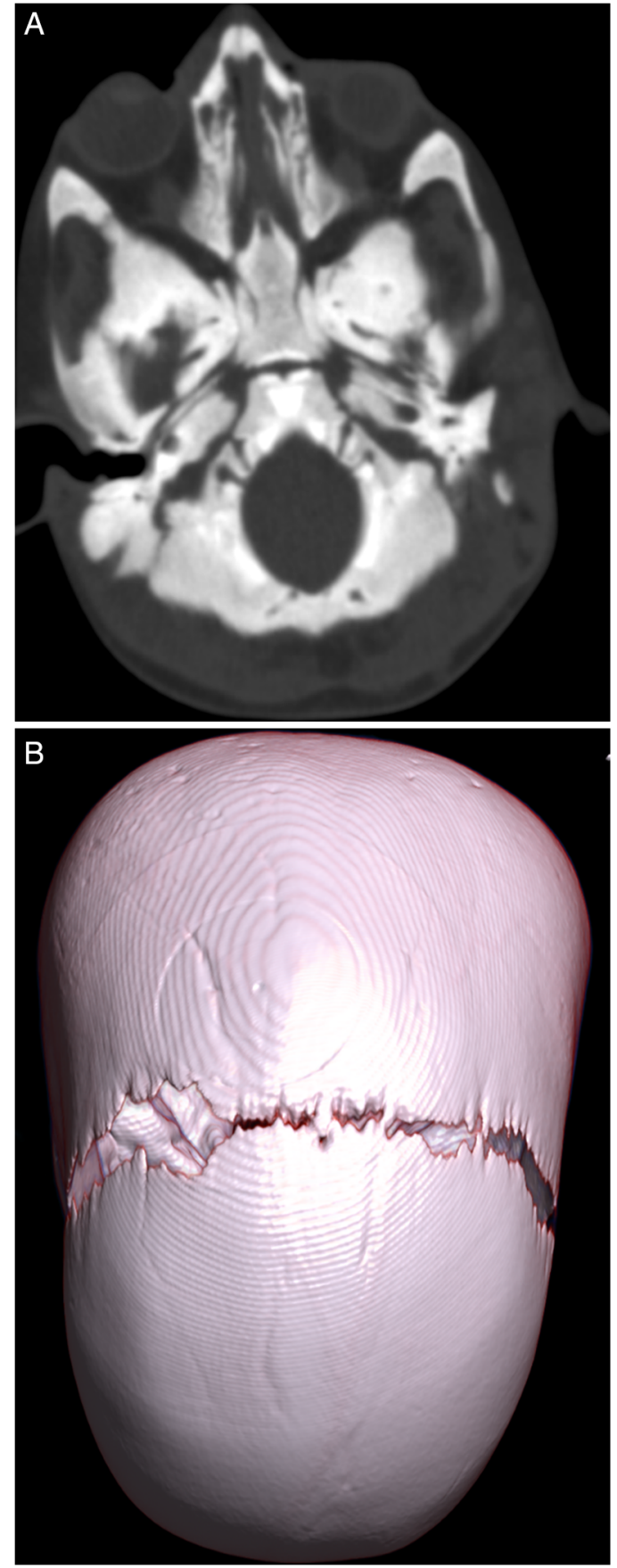

Figure 1 (A) Axial bone window section of CT of the head at the level of the base of the skull showing diffuse thickening and sclerosis of bones with obliteration of the diploic marrow space. There is resultant stenosis of various foramina of the base of the skull. (B) Volume rendered image showing premature fusion of the sagittal suture with increased anteroposterior diameter of the skull (scaphocephaly). Unfused coronal suture is seen. 

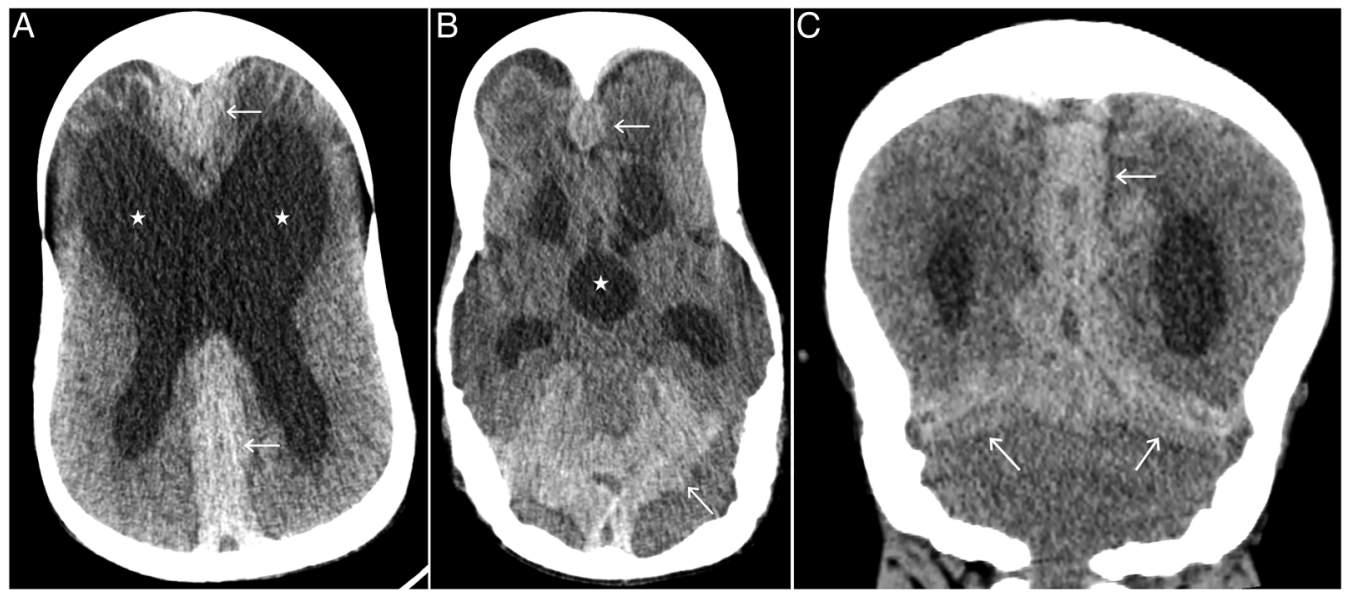

Figure 2 Axial cerebral window sections of non-contrast CT of the head (A and B) depict extensive thickening and calcification of the falx cerebri and tentorium cerebelli (arrows). Both lateral and third ventricles are dilated (asterisk) with periventricular hypodensity, suggestive of obstructive hydrocephalus. (C) Coronal reformatted images better demonstrating the calcification of dural structures (arrows).

tentorium cerebelli, which has been described in only three cases to date. ${ }^{3}$ Additionally, these findings contributing towards posterior fossa crowding with resultant aqueductal narrowing and hydrocephalus have been described only once before, with

\section{Learning points}

- Autosomal recessive osteopetrosis (AROP), or 'malignant' osteopetrosis, is an uncommon disease with a poor prognosis unless treated early with bone marrow transplantation.

- Cranial manifestations include skull thickening and sclerosis with resultant stenosis of skull base foramina and hydrocephalus.

- Thickening and calcification of the falx cerebri and tentorium cerebelli are extremely unusual causes of aqueductal stenosis and obstructive hydrocephalus in AROP. our case having more florid findings. ${ }^{3}$ Lastly, the index case also showed craniosynostosis, which has been rarely reported in AROP.

Unfortunately, the patient was lost to follow-up. However, this case, apart from demonstrating many of the classical cranial manifestations of AROP, also highlights a rare finding as an additional cause of hydrocephalus in such patients.

Competing interests None declared.

Patient consent Obtained.

Provenance and peer review Not commissioned; externally peer reviewed.

\section{REFERENCES}

1 Curé JK, Key LL, Goltra DD, et al. Cranial MR imaging of osteopetrosis. AJNR Am J Neuroradiol 2000;21:1110-15.

2 Scott WW, Weprin BE, Swift DM. A unifying theory for the multifactorial origin of cerebellar tonsillar herniation and hydrocephalus in osteopetrosis. J Neurosurg Pediatr 2014; 14:665-73.

3 Turgut $\mathrm{M}$, Aral $\mathrm{YZ}$, Özsunar $\mathrm{Y}$, et al. Autosomal recessive osteopetrosis as an unusual cause of hydrocephalus, extensive calcification of tentorium cerebelli, and calvarial hyperostosis. J Neurosurg Pediatr 2010;5:419-21.

Copyright 2015 BMJ Publishing Group. All rights reserved. For permission to reuse any of this content visit http://group.bmj.com/group/rights-licensing/permissions.

BMJ Case Report Fellows may re-use this article for personal use and teaching without any further permission.

Become a Fellow of BMJ Case Reports today and you can:

- Submit as many cases as you like

- Enjoy fast sympathetic peer review and rapid publication of accepted articles

- Access all the published articles

- Re-use any of the published material for personal use and teaching without further permission

For information on Institutional Fellowships contact consortiasales@bmjgroup.com

Visit casereports.bmj.com for more articles like this and to become a Fellow 